\title{
A GIS-based approach to identify the spatial variability of salt affected soil properties and delineation of site-specific management zones: A case study from Egypt
}

\author{
Mohamed K. Abdel-Fattah ${ }^{*}$ \\ 1 Zagazig University, Faculty of Agriculture, Soil Science Department, Zagazig City, Sharkia Governorate, Egypt, Postal Code 44511, \\ Egypt \\ * Mohamed K. Abdel-Fattah, mohammedkamal8@yahoo.com, ORCID iD: https://orcid.org/0000-0002-3705-4817
}

Received: August 29, 2019

Accepted: March 16, 2020

Associated editor: C. Kabała

\section{Keywords}

Spatial variability

Kriging

Site-specific management zones

Salt affected soils

\begin{abstract}
Electrical conductivity of the soil saturated paste extract $\left(\mathrm{EC}_{\mathrm{e}}\right)$, $\mathrm{pH}$ and exchangeable sodium percentage (ESP) are most important soil properties to determine and design methods of salt-affected soil reclamation. Surface soil samples from 125 locations in Sahl El-Husseinia, El-Sharkia Governorate, Egypt were taken using hand auger and analyzed for EC,, HH, SAR, ESP and CEC. GPS device was used to record the latitude and longitude of each sampling point. Principal component analysis (PCA) was used to summarize soil properties. ArcGIS software was used to assess spatial distribution pattern of different soil properties. Interpolation mapping to estimate the values of soil properties at un-sampled locations was conducted using ordinary kriging procedure and semi-variogram models were evaluated. Agglomerative hierarchical clustering technique was utilized to define soil management zones. Observed positive strong significant correlation between $\mathrm{EC}_{\mathrm{e}}$ and other attributes of soil (i.e. ESP, SAR and CEC) with the exception of $\mathrm{pH}$. The PCA resulted that there are two principal components (PCs) explained $80.27 \%$ of the total variance of soil properties. The first PC (explained $59.64 \%$ of variability) was strongly influenced by soil EC $\mathrm{e}$, SAR, ESP and CEC whereas the second PC showed a more intense relation with $\mathrm{pH}$ only. Soil $\mathrm{EC}_{\mathrm{e}}, \mathrm{pH}$ and $\mathrm{CEC}$ were pentaspherical, exponential and stable respectively as a best-fit model. Meanwhile, the Spherical model was the best-fit model to SAR and ESP. Based on agglomerative hierarchical clustering, three soil management zones (SMZ) were selected differing significantly with respect to studied soil properties. Calculations for each SMZ concerning gypsum requirements (GR) to reduce ESP to 10 as well as water amount were carried out to reduce $\mathrm{EC}_{\mathrm{e}}$ to $2 \mathrm{dS} \mathrm{m}^{-1}$. The amounts of GR are $6.10,7.05$ and $13.37 \mathrm{Mg} \mathrm{ha}^{-1}$ for SMZ1, SMZ2 and SMZ3, respectively. The amounts of leaching water requirements (LR) for leaching salts from the soil are $2.98,4.25$ and $5.57 \mathrm{~m}^{3} \mathrm{ha}^{-1}(\times 1000)$ for SMZ1, SMZ2 and SMZ3 respectively.
\end{abstract}

\section{Introduction}

Spatial variability is important in evaluating soil chemical and physical soil properties and how these change with location as well as identifying how to take soil samples (Elaalem, 2017). Understanding soil spatial variability is necessary for site-specific management (Bekele and Hudnall, 2006; Jabro et al., 2010; Cruz et al., 2011) and can help in managing productivity of arable lands tailoring agricultural inputs to fit the spatial requirements of soils and crops (Fraisse et al., 1999). The main objective of studying spatial variability of soil characteristics is to predict different soil properties at un-sampled locations and management practices in the light of variations of this kind (De la Rosa, 1979; Burrough, 1989; White et al., 1997; Talkkari et al., 2002; Elaalem, 2017).
Geographic information system (GIS) effectively helped in assessments of spatial variability and it proved useful in understanding and explaining different soil properties (Burrough, 1983; Fahad, 1993; Hosseini et al., 1994; Usowicz et al., 2004; Corwin and Lesch, 2005; Camacho-Tamayo et al., 2008; Santra et al., 2008;). Interpolation methods such as the inverse distance weighting (IDW) and kriging method found in the GIS environment have enabled spatial prediction of sites in high accuracy and quality (Elaalem, 2017). Kriging, for example, is a method of prediction in geographic space and is considered as the most appropriate linear unbiased predictor. On the other hand, the most commonly-used method is ordinary kriging (OK) (Heap, 2008; Oliver, 2010) and assumes that the expected value (mean) of the interpolation field is an unknown constant. It is usually preferred to simple kriging 
(SK) because of the following (Goovaerts, 1997): 1) it requires neither knowledge nor stationarity of the mean over the region of interest, 2) it allows accounting for local variations, 3) it has more representing estimates than SK estimates and 4) it estimates change proportionally with the local data means, hence the OK with local search neighborhood already accounts for trends (varying mean) in the values of the primary variable. However, OK method requires a stationary mean of the local search window. If the data non-stationary could be used regression kriging (RK), universal kriging (UK) and Kriging with an external drift (KED) with such data (Stein et al., 1988; Knotters et al., 1995; Verfaillie et al., 2006). OK and UK yield similar interpolating yet quite different extrapolating estimates, depending on the trend fitted to the last few data values (Goovaerts, 1997). OK with local search neighborhoods is preferred in interpolations because it provides results similar to UK estimates though is easier to implement.

Understanding spatial salinity-sodicity variability across extended locations is essential in optimizing amendment applications needed for reclamation. The objectives of the current study were 1) to characterize the spatial variability across soils in Sahl El-Husseinia and 2) to establish management zones using agglomerative hierarchical clustering (AHC).

\section{Materials and methods}

\subsection{Study area and soil sampling}

The study was carried out in El-Husseinia area, north west part of Sharqia Governorate, Egypt which bounded by $31^{\circ} 47^{\prime} 30^{\prime \prime}$ \& $32^{\circ} 11^{\prime} 30^{\prime \prime} \mathrm{E}$ and $30^{\circ} 44^{\prime} 30^{\prime \prime} \& 31^{\circ} 11^{\prime} 30^{\prime \prime} \mathrm{N}$ (Fig. 1) covering an area of $1559 \mathrm{~km}^{2}$ (31\% of total area of the governorate). The climatic data which collected from Port Said and Ismailia Station show that the maximum temperatures ranged from 31.9 to $37.1^{\circ} \mathrm{C}$ in August; meanwhile the lower were 9.7 to $13.1^{\circ} \mathrm{C}$ in January. The average annual temperature $22.5^{\circ} \mathrm{C}$ and $22.8^{\circ} \mathrm{C}$ according to Port Said and Ismailia meteorological stations respectively with a wide difference between summer and winter months. Total annual rainfall ranged from 33.3 to $73.3 \mathrm{~mm}$. The precipitation is not equally distribution throughout the rainy season. The maximum was recorded in November and December (ranged from 7.7 to $18 \mathrm{~mm}$ ). the values of relative humidity varied from 68.4 to $74.8 \%$ and 47.4 to $69.8 \%$ according to Port Said and Ismailia stations respectively. The wind velocity ranged between 14.2 and $18.7 \mathrm{~km} \mathrm{~h}^{-1}$ at Port Said station was recorded in September and March respectively. According to Ismailia station it was 10 and $17.1 \mathrm{~km} \mathrm{~h}^{-1}$ in November and March respectively.

A number of 125 soil samples were taken from 0-30 cm depth of locations in Sahl El- Husseinia, El-Sharkia Governorate, Egypt representing five villages Tariq-Bin-Ziyad, Al- Slah, Khaled-BinWalid, El-Azhar and AL-Rowad. 25 samples were taken from each village. GPS device was used to record the latitude and longitude of each sampling point. Samples were analyzed for $\mathrm{EC}_{\mathrm{e}}$, soluble ions , $\mathrm{pH}$ and CEC according to the methods described by (Richards, 1969) and (Van Reeuwijk, 2002). Soil pH was determined in 1:2.5 soil-water extract and electrical conductivity $\left(\mathrm{EC}_{\mathrm{e}}\right)$ was determined in the soil saturated paste extract.
The sodium adsorption ratio (SAR) and the exchangeable sodium percentage (ESP) were computed using results of cations (i.e. $\mathrm{Na}^{+}, \mathrm{Ca}^{2+}$ and $\mathrm{Mg}^{2+}$ which expressed as $\mathrm{mmol}_{\mathrm{c}} \mathrm{l}^{-1}$ ) as follows (Richards, 1969; Van Reeuwijk, 2002).

$$
\begin{aligned}
& S A R=\frac{N a^{+}}{\sqrt{\frac{C a^{2+}+M g^{2+}}{2}}} \\
& E S P=\frac{1.475 \times \mathrm{SAR}-1.26}{0.01475 \times \mathrm{SAR}+0.9874}
\end{aligned}
$$

\subsection{Statistical analysis of data and principal component analysis}

Data were statistically analyzed for descriptive measurements including arithmetic mean, median, mode, maximum, minimum, range, variance, standard deviation, standard error, coefficient of variation, skewness and kurtosis.

Before principal component analysis (PCA), normality of variables was checked using the Shapiro-Wilk test and correlation between different variables was measured by Pearson correlation. Also, Bartlett's sphericity test as well as Kaiser-Meyer-Olkin Measure of Sampling Adequacy (KMO) was conducted to verify data dependence, where If the KMO result is larger than 0.5 and $p$

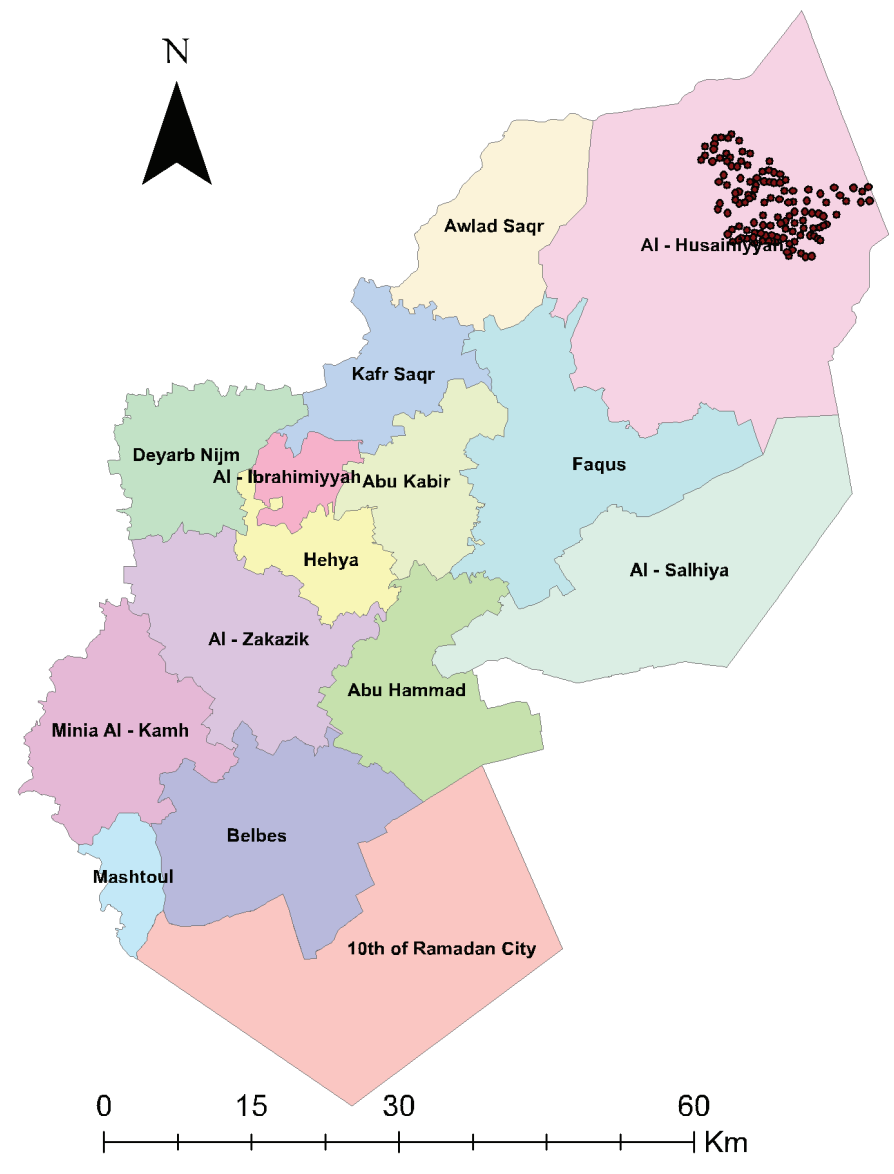

Fig. 1. Location of the study area with sampling points. 
value of Bartlett's sphericity test is smaller than 0.05 , this indicates the non-mutual independence of data and can be applied for PCA.

Soil properties were summarized using PCA. The PCA was performed using XLSTAT software version 2016. PCA is a statistical procedure that uses an orthogonal transformation to convert a set of observations of possibly correlated variables (entities each of which takes on various numerical values) into a set of values of linearly uncorrelated variables called principal components (PCs). PCs having eigenvalues greater than one has been retained whereas PCs less than 1 was subtracted away (Abdi and Williams, 2010).

\subsection{Geostatistical analysis}

ArcGIS 10.2.1 software was used to assessment of spatial distribution pattern of different soil properties (i.e. $\mathrm{EC}_{\mathrm{e}}, \mathrm{pH}, \mathrm{SAR}$, ESP and CEC). Interpolation mapping to estimate values of soil properties for un-sampled locations was done using ordinary kriging (Goovaerts, 1998). Semi-variogram models can be used with ordinary kriging (OK) like other kriging methods. Semi-variogram for each soil property was calculated as follows:

$$
\gamma(\mathrm{h})=\frac{1}{2 \mathrm{~N}(\mathrm{H})} \sum_{\alpha=1}^{\mathrm{N}(\mathrm{h})}\left[\mathrm{Z}\left(\mathrm{X}_{\alpha}+\mathrm{h}\right)\right]^{2}
$$

Where $\gamma(h)$ represent sem-ivariance for the lag distance $h$, $\mathrm{N}(\mathrm{h})$ represent number of sample pairs separated by the lag distance $h, z(x a)$ represent measured value at ath sample location and $z(x a+h)$ represent measured value at point $\alpha+$ hth sample location.

Different semi-variogram models (i.e. Stable, J-Bessel, K-Bessel, Hole Effect, Rational Quadratic, Gaussian, Exponential, Pentaspherical, Tetraspherical, Spherical and Circular) were evaluated based on many criteria such as strong spatial dependence (SDC), Mean error (ME), Root-Mean-Square error (RMSE), Mean Standardized error (MSE), Root-Mean-Square Standardized error (RMSSE) and Average Standard Error (ASE). Generally, the best fit model which have mean error "ME", mean standardized error "MSE" and average standard error "ASE” values close to zero and root mean square standardized error "RMSSE" close to one (Gundogdu and Guney, 2007). The equations are as follows (Johnston et al., 2001)

$$
\begin{aligned}
& M E=\frac{1}{N} \sum_{i=1}^{N}\left[Z\left(x_{i}\right)-Z\left(\hat{x}_{i}\right)\right] \\
& M S E=\frac{1}{N} \sum_{i=1}^{N} \frac{Z\left(x_{i}\right)-Z\left(\hat{x}_{i}\right)}{\sigma(i)} \\
& A S E=\sqrt{\frac{1}{N} \sum_{i=1}^{N} \sigma(i)}
\end{aligned}
$$

$$
\begin{aligned}
& \text { RMSE }=\sqrt{\frac{1}{N} \sum_{i=1}^{N}\left[Z\left(x_{i}\right)-\hat{Z}\left(x_{i}\right)^{2}\right]} \\
& \text { RMSSE }=\sqrt{\frac{1}{N} \sum_{i=1}^{N}\left\{\frac{Z\left(x_{i}\right)-\hat{Z}\left(x_{i}\right)}{\sigma(i)}\right\}^{2}}
\end{aligned}
$$

where $\hat{Z}\left(x_{i}\right), Z\left(x_{i}\right), \mathrm{n}$ and $\sigma$ are refer to the predicted value, the observed value, the number of values and standard error for location $i$ respectively.

Regarding SDC which defined as nugget $\left(\mathrm{C}_{0}\right)$ to sill $\left(\mathrm{C}_{0}+\mathrm{C}\right)$ ratio, if nugget to sill ratio was $<0.25,0.25-0.75$ and $>0.75$, reveal strong (attributed to intrinsic factors), moderate (attributed to both intrinsic and extrinsic factors) and weak (attributed to extrinsic factors) spatial dependence respectively (Cambardella et al., 1994).

\subsection{Determination of site-specific management zones}

Agglomerative hierarchical clustering (AHC) was applied to define soil management zones. XLSTAT software version 2016 was used to classify the data into different clusters having a common trait. The study area was divided into three clusters using AHC. A one-way ANOVA test was performed for comparison between soil management zones and followed by post hoc test using Duncan multiple range (DMR) test for comparisons between management zones.

\section{Results and discussion}

\subsection{Characterization of the studied soil}

Most of the salt affected soils reclamation indicators $\left(\mathrm{EC}_{\mathrm{e}}\right.$, $\mathrm{pH}, \mathrm{SAR}$ and ESP) for the collected samples were presented in Table 1 . The values of studied soil properties varied widely. The mean values were $12.48 \pm 0.38$ (ranged from 19.53 to $5.48 \mathrm{dSm}^{-1}$ ), $7.98 \pm 0.03$ (ranged from 8.65 to 7.23), $14.54 \pm 0.24$ (ranged from 23.56 to 10.23 ), $16.71 \pm 0.24 \%$ (ranged from 25.09 to $12.15 \%$ ) and $31.65 \pm 0.36 \mathrm{cmol}_{\mathrm{c}} \mathrm{kg}^{-1}$ soil (ranged from 38.69 to $20.62 \mathrm{cmol}_{\mathrm{c}} \mathrm{kg}^{-1}$ soil) for soil EC $\mathrm{E}_{\mathrm{e}}, \mathrm{pH}, \mathrm{SAR}, \mathrm{ESP}$ and CEC respectively. These results show that studied soil is located within the saline and saline sodic soils categories. The term salt-affected soil is more commonly used to include saline non sodic (non-alkali), saline-sodic (alkali) and non-saline sodic (alkali) soils, which are clearly differentiated by Richards (1969). The term "alkali” to describe soils with excess exchangeable sodium was deemed improper due to its ambiguity (Overstreet et al., 1951). Saline non-sodic soils are those which have $\mathrm{EC}_{\mathrm{e}}>4 \mathrm{dS} \mathrm{m}^{-1}$, ESP $<15$ and $\mathrm{pH}<8.5$. Saline-sodic soils have $\mathrm{EC}_{\mathrm{e}}>4 \mathrm{dS} \mathrm{m}^{-1}$ and ESP $>15$ but Their $\mathrm{pH}$ may be less or more than 8.5 if they contain such high contents of salts to prevent hydrolysis of sodic-salts. They may also have $\mathrm{pH}>8.5$ if their salinity is not excess is very high. Non-saline sodic soils have $\mathrm{EC}_{\mathrm{e}}<4 \mathrm{dS} \mathrm{m}^{-1}$, ESP $>15$ and $\mathrm{pH}>8.5$ and may reach as high as 11 . 
Table 1. Descriptive statistical parameters and normality test of the study area

\begin{tabular}{|c|c|c|c|c|c|c|c|}
\hline \multicolumn{3}{|c|}{ Descriptive statistical } & \multicolumn{5}{|c|}{ Soil properties } \\
\hline & & & $\begin{array}{r}\mathrm{EC}, \\
\mathrm{dS} \mathrm{m}^{-1}\end{array}$ & $\mathrm{pH}$ & SAR & ESP & $\begin{array}{r}\text { CEC, } \\
\mathrm{cmol}_{\mathrm{c}} \mathrm{kg}^{-1}\end{array}$ \\
\hline \multicolumn{3}{|c|}{ Arithmetic Mean } & 12.48 & 7.85 & 14.54 & 16.71 & 31.65 \\
\hline \multicolumn{3}{|l|}{ Median } & 11.99 & 7.88 & 13.56 & 15.78 & 32.08 \\
\hline \multicolumn{3}{|l|}{ Mode } & 19.53 & 7.89 & 12.56 & 14.72 & 34.55 \\
\hline \multicolumn{3}{|l|}{ Maximum } & 19.53 & 8.30 & 23.56 & 25.09 & 38.69 \\
\hline \multicolumn{3}{|l|}{ Minimum } & 5.48 & 7.23 & 10.23 & 12.15 & 20.62 \\
\hline \multicolumn{3}{|l|}{ Range } & 14.05 & 1.07 & 13.33 & 12.94 & 18.07 \\
\hline \multicolumn{3}{|l|}{ Variance } & 17.92 & 0.04 & 7.24 & 7.10 & 16.00 \\
\hline \multicolumn{3}{|c|}{ Standard deviation } & 4.23 & 0.20 & 2.69 & 2.66 & 4.00 \\
\hline \multicolumn{3}{|c|}{ Standard error } & 0.38 & 0.02 & 0.24 & 0.24 & 0.36 \\
\hline \multicolumn{3}{|c|}{ Coefficient of variation } & 33.91 & 2.52 & 18.51 & 15.94 & 12.64 \\
\hline \multicolumn{3}{|l|}{ Skewness } & 0.08 & -0.42 & 1.07 & 0.93 & -0.44 \\
\hline \multicolumn{3}{|l|}{ Kurtosis } & -1.23 & 0.61 & 0.76 & 0.28 & -0.27 \\
\hline \multirow{6}{*}{$\begin{array}{l}\text { Normality } \\
\text { test }\end{array}$} & \multirow{3}{*}{$\begin{array}{l}\text { Shapiro-Wilk } \\
\text { test }\end{array}$} & Statistic & 0.94 & 0.97 & 0.893 & 0.908 & 0.979 \\
\hline & & $\mathrm{df}$ & 125 & 125 & 125 & 125 & 125 \\
\hline & & Sig. & 0.00 & 0.00 & 0.00 & 0.00 & 0.054 \\
\hline & \multirow{3}{*}{$\begin{array}{l}\text { Kolmogorov } \\
\text { test }\end{array}$} & Statistic & 0.096 & 0.116 & 0.170 & 0.165 & 0.062 \\
\hline & & $\mathrm{df}$ & 125 & 125 & 125 & 125 & 125 \\
\hline & & Sig. & 0.07 & 0.00 & 0.00 & 0.00 & 0.200 \\
\hline
\end{tabular}

The Kolmogorov-Smirnov and the Shapiro-Wilk Tests result showed that the soil properties (EC, $\mathrm{pH}, \mathrm{SAR}, \mathrm{ESP}$ and CEC) are not normally distributed ( $p$ values $<0.05$ ). Therefore before making spatial distribution of soil properties by ordinary kriging (OK) method, the data was transformed using the Two-Step method (Templeton, 2011). Fig. 2 shows the distribution of data before and after transformation on histogram.
Fig. 2. EC, pH, SAR, ESP and CEC values in histogram before and after data transformation
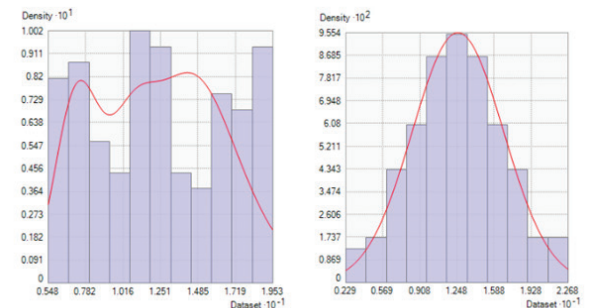

EC Values before and after data transformation
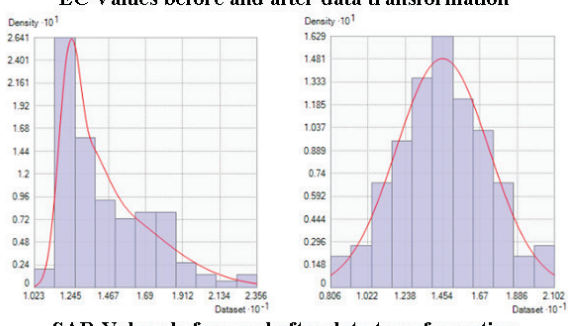

SAR Values before and after data transformation
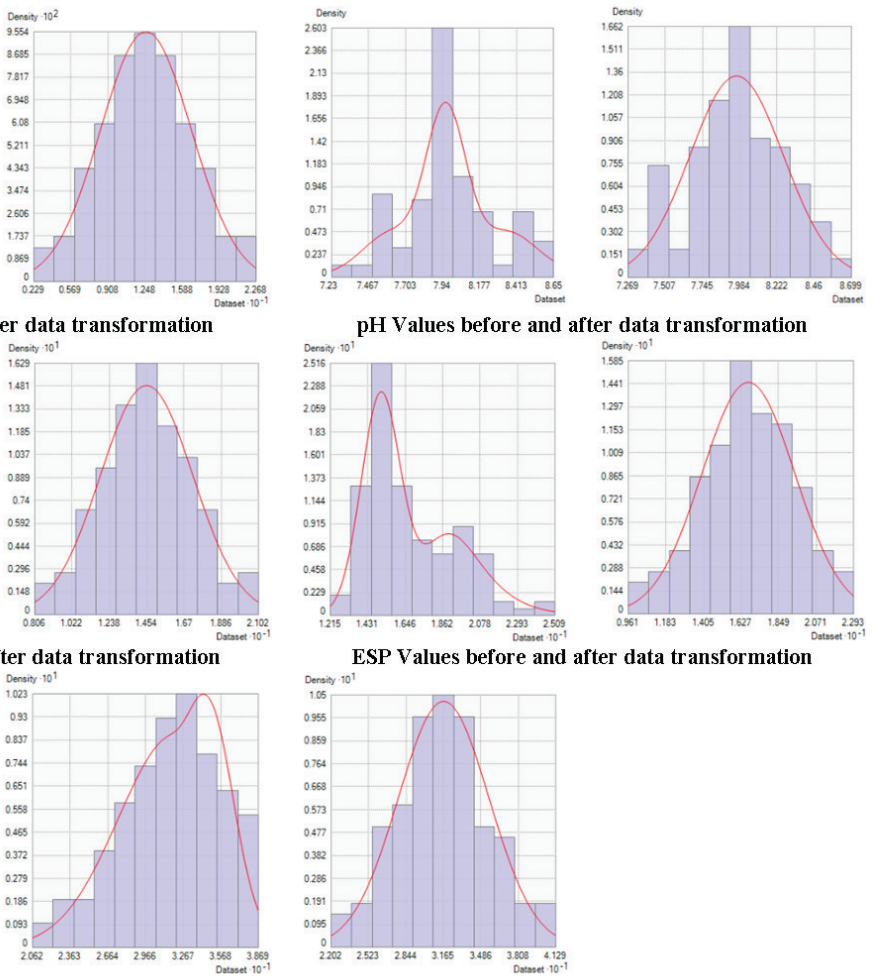

$\mathrm{pH}$ Values before and after data transformation
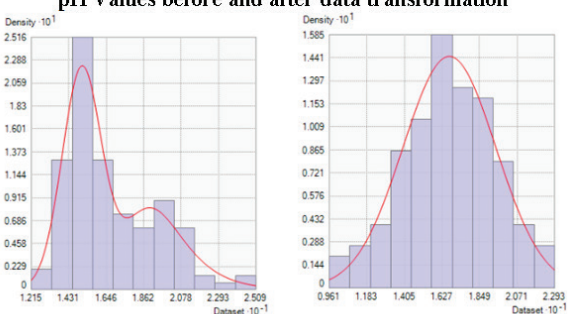

ESP Values before and after data transformation

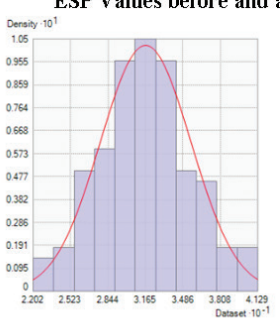

CEC Values before and after data transformation 


\subsection{Association between soil properties}

A Pearson correlation test was carried out to study the relationship between different properties of soil i.e. $\mathrm{EC}_{\mathrm{e}}, \mathrm{pH}, \mathrm{SAR}, \mathrm{ESP}$ and CEC (Table 2). It was observed that there were positive strong significant correlations between $\mathrm{EC}_{\mathrm{e}}$ and other properties except $\mathrm{pH}$. Salinity is an indirect measurement of many soil properties affecting soil fertility and crop yield (Corwin and Lesch, 2005). Soil $\mathrm{EC}_{\mathrm{e}}$ differentiates soil types for site-specific management (Behera et al., 2018). This can be confirmed from these correlations be-

Table 2. Correlation matrix to study the Association between different soil properties, Results of Bartlett's sphericity test and KMO measure of sampling adequacy

\begin{tabular}{llccc}
\hline Variables & EC & pH & SAR & ESP \\
\hline $\mathrm{pH}$ & 0.15 & & & \\
SAR & $0.74^{* * *}$ & $0.18^{*}$ & & \\
ESP & $0.73^{* * *}$ & $0.18^{*}$ & $0.99^{* * *}$ & \\
CEC & $0.57^{* * *}$ & -0.03 & $0.38^{* * *}$ & $0.38^{* * *}$ \\
\hline
\end{tabular}

Bartlett's sphericity test and KMO measure of sampling adequacy KMO measure of sampling adequacy 0.65

\section{Bartlett's sphericity test}

Chi-square (Observed value)

928.69

Chi-square (Critical value)

18.31

DF (Degree of freedom)

10.00

p-value

alpha

$<0.0001$

0.05

tween the different variables using biplot (Fig. 3), where the angles between the vectors tell us how characteristics correlate with one another. When two vectors are close, forming a small angle, the two variables they represent are positively correlated. If they meet each other at $90^{\circ}$, they are not likely to be correlated. When they

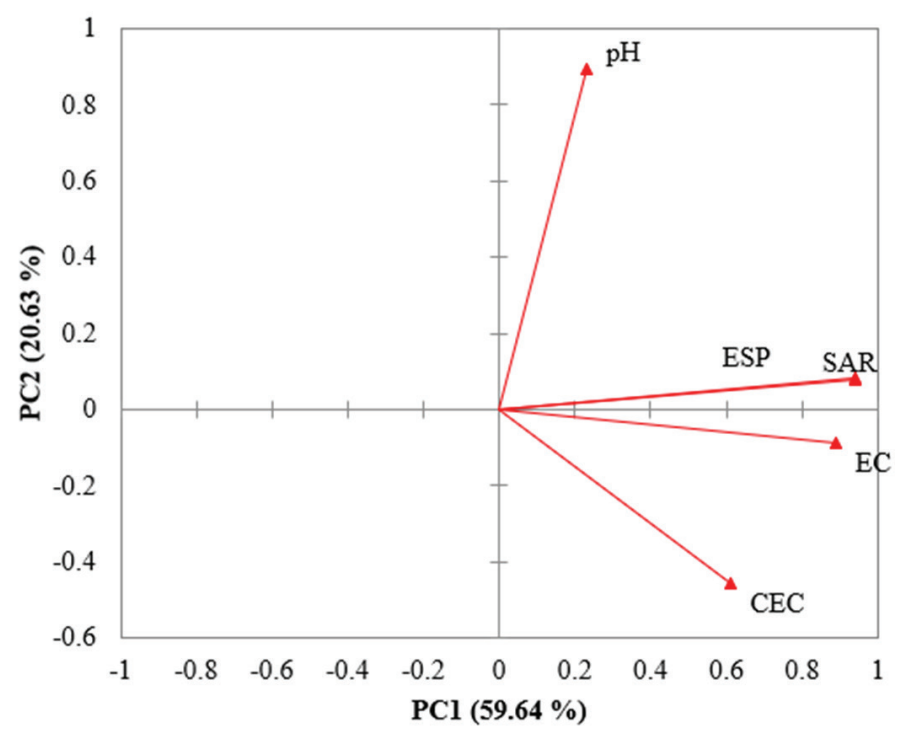

Fig. 3. Principal component analysis bi-plot (PC1 vs PC2) of soil properties of the study area. diverge and form a large angle (close to $180^{\circ}$ ), they are negative correlated. The vast majority of these correlations were significant ( $p<0.05$ ), indicating that one or more major general components to these variables present. Due to the strong correlation between different soil properties, principle components analysis (PCA) was conducted to derive principal sources of data variability. Also, this can be verified by Bartlett's sphericity test and KMO test (Table 2), where small $p$ values $(p<0.05)$ of the significance level indicate that a PCA may be useful with your data. Bartlett's sphericity test result is present in Table 2. Observed the $\mathrm{p}$ value is lower than 0.001 . The KMO values was greater than 0.5 indicates that a PCA may be useful. Accordingly, the PCA may be useful with our data.

\subsection{Principle components analysis (PCA)}

Soil properties were summarized using principal component analysis (PCA). PCs having eigenvalues greater than one was retained whereas PCs less than 1 was subtracted. Therefore the first two PCs were retained, whereas these PCs together explained $80.27 \%$ of the total variance of data (Table 3 and Fig. 3 ). The first PC (59.64\% of variability) is strongly affected by EC, , SAR, ESP and CEC, with exception of $\mathrm{pH}$. Due to relations between the $\mathrm{EC}_{\mathrm{e}}$, SAR, ESP and CEC and this PC, regions with lower values for this $\mathrm{PC}$ are the most to reclaim. The second PC showed a more intense relation with $\mathrm{pH}$ only, approximately the contrary of the first PC, for which the relative influence of $\mathrm{pH}$ was low.

Table 3. Principal component analysis of soil properties and loading coefficient for the principal components and Correlation with principal components (PC1 and PC2)

\begin{tabular}{lccccr}
\hline & PC1 & PC2 & PC3 & PC4 & PC5 \\
\hline Eigenvalue & 2.98 & $\mathbf{1 . 0 3}$ & 0.72 & 0.27 & 0.001 \\
Variability (\%) & 59.6 & 20.6 & 14.4 & 5.37 & 0.016 \\
Cumulative \% & 59.6 & 80.3 & 94.6 & 99.98 & 100 \\
Variables & Correlation with & principal components \\
EC & (PC1 and PC2) & & & \\
pH & $\mathbf{0 . 8 8}$ & -0.09 & - & - & - \\
SAR & 0.23 & $\mathbf{0 . 9 0}$ & - & - & - \\
ESP & $\mathbf{0 . 9 4}$ & 0.08 & - & - & - \\
CEC & $\mathbf{0 . 9 4}$ & 0.08 & - & - & - \\
\hline
\end{tabular}

Note: Loading in an absolute value greater than 0.50 is highlighted in bold

\subsection{Semi-variogram parameters}

Table 4 and Fig. 4 show the parameters of semi-variograms. The best fit model with mean error "ME", mean standardized error "MSE" and average standard error "ASE” values close to zero and root mean square error "RMSE" are close to one (Gundogdu and Guney, 2007). Soil EC, $\mathrm{pH}$ and CEC are pentaspherical, exponential and stable respectively as a best-fit model whereas the Spherical model was the best-fit model to SAR and ESP. 
Table 4. Semi-variogram parameters of the soil properties of the study area

\begin{tabular}{|c|c|c|c|c|c|c|c|c|c|c|c|c|}
\hline Variable & Model & $\begin{array}{l}\text { Nugget } \\
\left(\mathrm{C}_{0}\right)\end{array}$ & $\begin{array}{r}\text { Partial } \\
\text { sill }\end{array}$ & $\begin{array}{r}\text { Sill } \\
\left(\mathrm{C}_{0}+\mathrm{C}\right)\end{array}$ & $\begin{array}{r}\text { Nugget/ } \\
\text { Sill }\end{array}$ & $\begin{array}{l}\text { Major } \\
\text { Range }\end{array}$ & SDC & ME & RMSE & MSE & RMSSE & ASE \\
\hline $\mathrm{EC}$ & Pentaspherical & 2.39 & 12.93 & 15.32 & 0.16 & 1859.60 & Strong & -0.07 & 3.27 & -0.014 & 0.94 & 3.60 \\
\hline $\mathrm{PH}$ & Exponential & 0.03 & 0.09 & 0.12 & 0.23 & 4083.25 & Strong & -0.00071 & 0.28 & -0.002 & 1.03 & 0.27 \\
\hline SAR & Spherical & 1.71 & 6.08 & 7.79 & 0.22 & 1947.74 & Strong & -0.04 & 2.40 & -0.02 & 1.01 & 2.43 \\
\hline ESP & Spherical & 1.96 & 6.19 & 8.15 & 0.24 & 1947.74 & Strong & -0.04 & 2.47 & -0.02 & 1.01 & 2.51 \\
\hline CEC & Stable & 0.00 & 17.64 & 17.64 & 0.00 & 9277.85 & Strong & -0.00342 & 3.03 & 0.002 & 0.94 & 3.20 \\
\hline
\end{tabular}

Notes: SDC, ME, RMSE, MSE, RMSSE and ASE refers to Strong spatial dependence, Mean error, Root-Mean-Square error, Mean Standardized error, Root-Mean-Square Standardized error and Average Standard Error

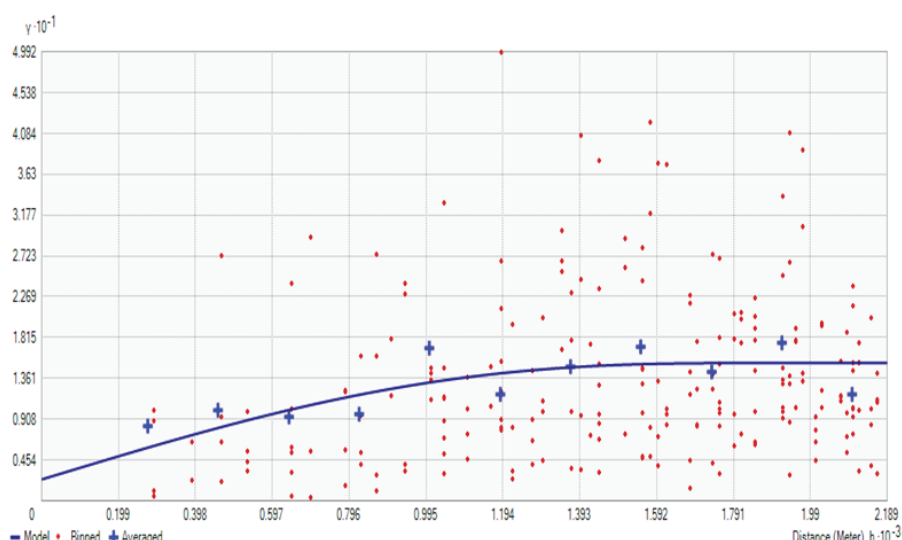

Spatial distribution for EC (Pentaspherical)

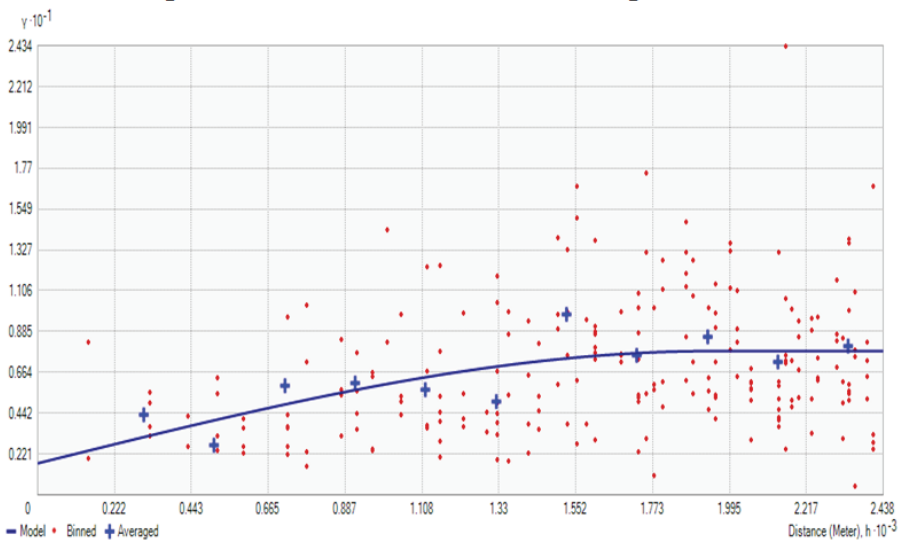

Spatial distribution for SAR (Spherical)

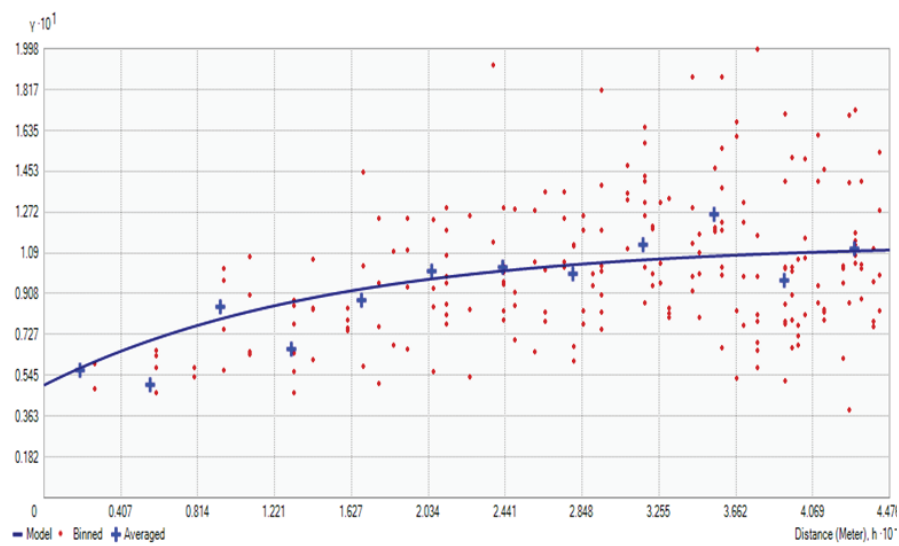

Spatial distribution for $\mathrm{pH}$ (Exponential)

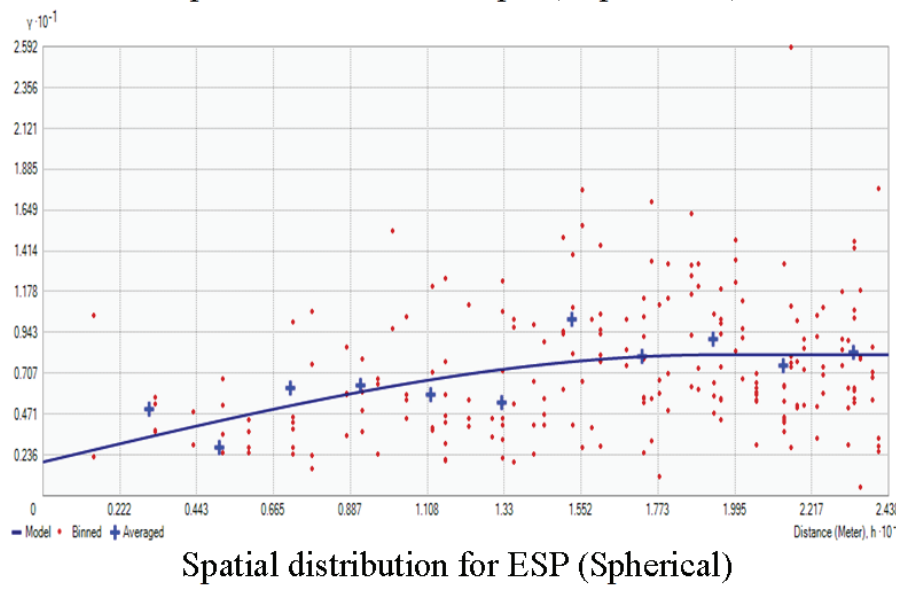

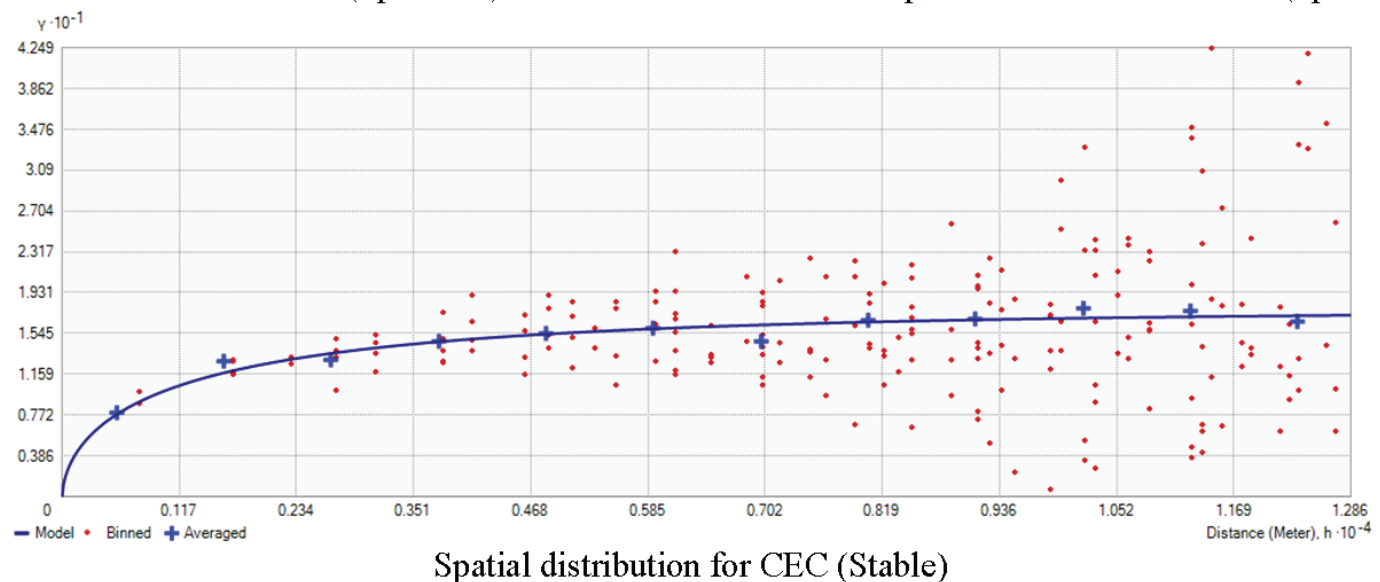

Fig. 4. Semi-variogram for EC, pH, SAR, ESP and CEC of the study area 
The nugget (which reveals the micro-variability) values were 2.39, 0.027, 1.71, 1.96 and 0 for soil $\mathrm{EC} e, \mathrm{pH}, \mathrm{SAR}$, ESP and CEC respectively. The sum of partial sill and nugget is called the sill. The Sill values indicating the variance of the sampled population at large separation distance if the data have no trend were also small (15.32 for $\mathrm{EC}_{\mathrm{e}}, 0.12$ for $\mathrm{pH}, 7.79$ for SAR, 8.15 for ESP and 17.63 for $\mathrm{CEC}$ ). If nugget-to-sill ratio was $<0.25,0.25-0.75$ and $>0.75$, this reveals strong (attributed to intrinsic factors), moderate (attributed to both intrinsic and extrinsic factors) and weak (attributed to extrinsic factors) spatial dependence respectively (Cambardella et al., 1994). According to nugget-to-sill ratio, Soil $\mathrm{EC}_{\mathrm{e}}, \mathrm{pH}, \mathrm{SAR}, \mathrm{ESP}$ and CEC had strong spatial dependence class. The strong spatial dependence of the soil properties is controlled by inherent soil characteristics like soil mineralogy and texture whereas extrinsic factors like soil management including tillage and fertilizer application influence moderate and weak spatial dependence of soil properties (Behera et al., 2018).

The range value of semi-variogram can be defined as the maximum distance within which there is autocorrelation or spatial dependence. The range values of studied soil properties varied from 1859.60 for $\mathrm{EC}_{\mathrm{e}}$ to $9277.85 \mathrm{~m}$ for CEC (Table 4). Beyond this value, there is no autocorrelation. Large range value reveals that measured soil properties are affected by natural and anthropogenic factors over greater distance than soil properties having smaller ranges (Behera et al., 2018; López-Granados et al., 2002). According to (Kerry and Oliver, 2004), soil sampling interval should be less than half the semi-variogram range value.

\subsection{Mapping Soil properties using ordinary kriging (OK) method}

The OK method was used for generation of spatial distribution maps of soil properties (Fig. 5). Soil properties showed different distributions and the distribution map revealed that $15.07 \%, 65.95 \%$ and $18.97 \%$ of studied area has an $\mathrm{EC}_{\mathrm{e}}<11,11$ to 14 and $>14 \mathrm{dS} \mathrm{m}^{-1}$ respectively and $12.18,80.45$ and $7.37 \%$ show a $\mathrm{pH}<7.83,7.83$ to 813 and $>8.13 \mathrm{dS} \mathrm{m}^{-1}$ respectively whereas 13.90 , 73.15 and $12.95 \%$ of studied area has an SAR $<13,13$ to 16 and $>16$ respectively. On the other hand, 7.07, 74.33 and $18.60 \%$ of the area has an ESP <15, 15 to 17 and $>17 \%$ respectively. Regarding CEC, spatial distribution map showed that $21.27,55.91$ and $22.82 \%$ of studied area has a CEC $<30,30$ to 33 and $>33 \mathrm{cmol}_{\mathrm{c}} \mathrm{kg}^{-1}$ soil respectively. These results show that studied soils are within the saline and saline sodic soils (Richards, 1969). The spatial distribution maps demonstrate variability of soil properties in the study area and these maps could be utilized for site-specific soil reclamation and management in the study area.

\subsection{Establishing management zones using soil properties}

The study area was divided into three clusters using XLSTAT based on AHC technique. Settings of XLSTAT software are shown in Fig 6. A dendrogram is a diagram that shows the hierarchical relationship between objects. It is most commonly created as an
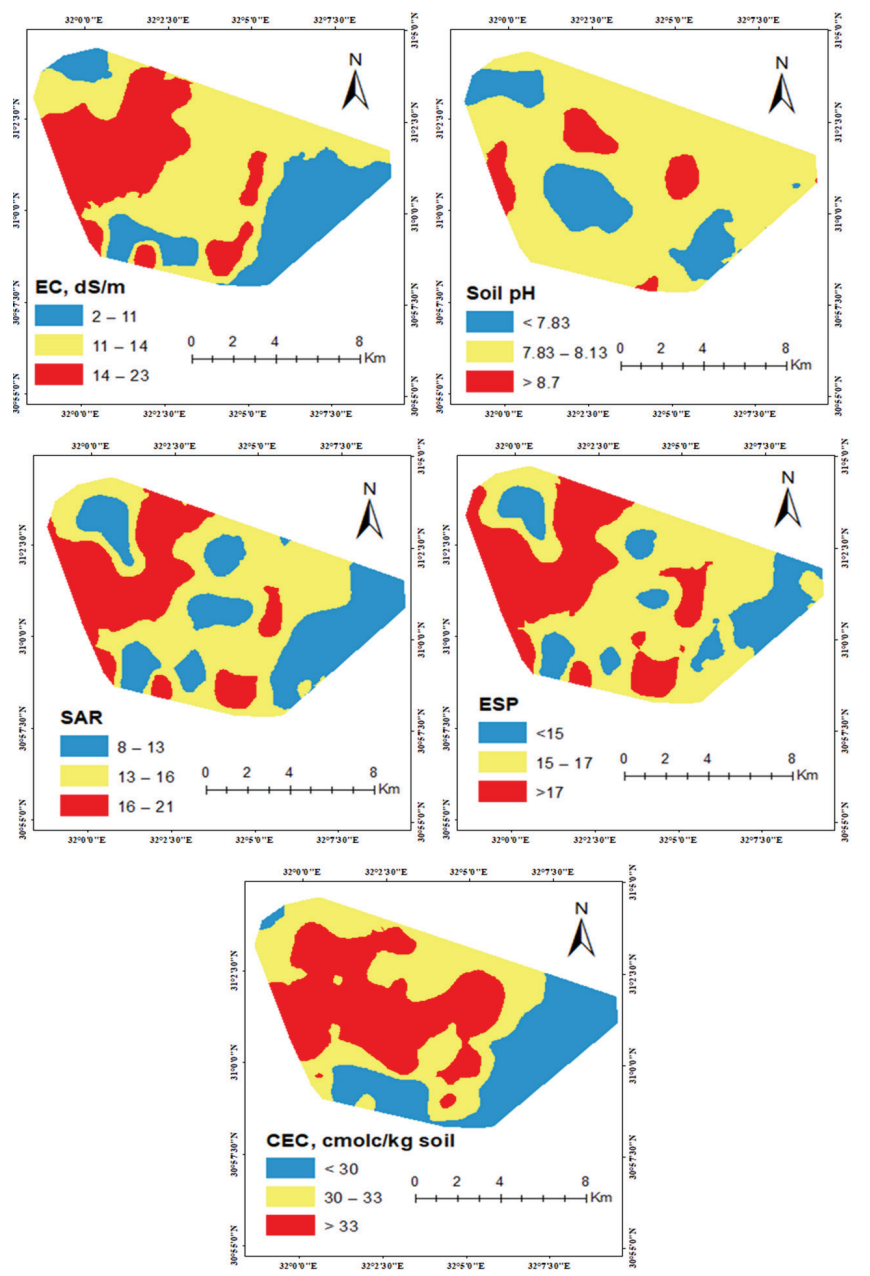

Fig. 5. Spatial distributions for EC, pH, SAR, ESP and CEC of the study area

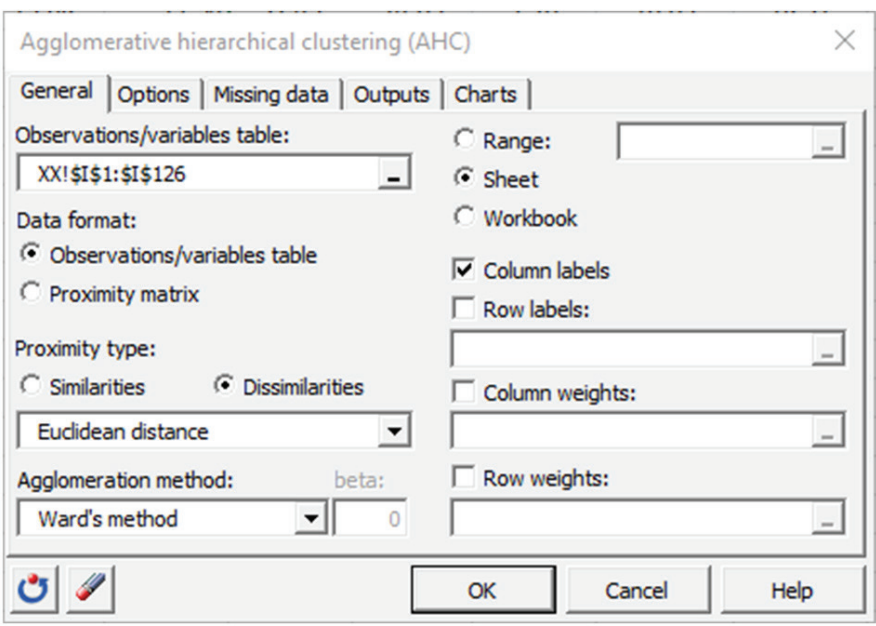

Fig. 6. Settings of XLSTAT software when running

output from Agglomerative hierarchical clustering (Fig. 7), this correlation can be seen in the abundance profiles of compounds from the same cluster.

The resultant maps show 3 soil management zones (SMZ) (Fig. 8). Table 5 reveals that the 3 SMZ were distinctly different 


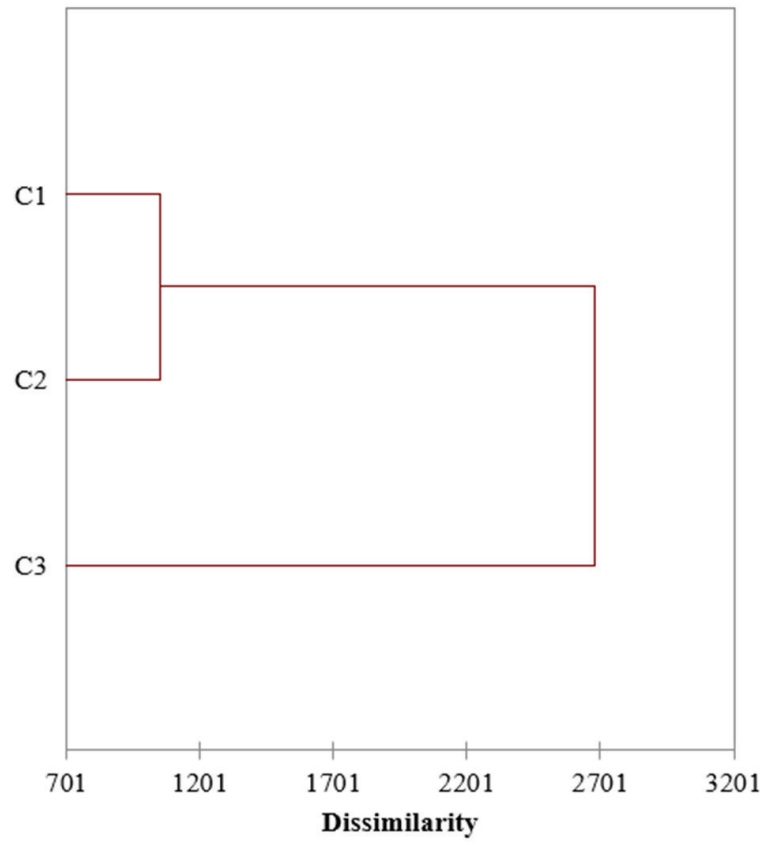

Fig. 7. Dendrogram for Agglomerative hierarchical clustering

from each other and that areas of SMZ1, SMZ 2 and SMZ 3 were $39.74,33.53$ and $26.74 \%$ respectively. Highest $\mathrm{EC}_{\mathrm{e}}$ was $17.08 \mathrm{dS} \mathrm{m}^{-1}$, highest pH was 8.07 whereas highest SAR was 17.44 and highest ESP was 19.46 and highest CEC was $33.88 \mathrm{cmol}_{\mathrm{c}} \mathrm{kg}^{-1}$.

According to (Richards, 1969), SMZ1, SMZ2 and MSZ3 are considered saline sodic soils. The amounts of agricultural gypsum are 6.10, 7.05 and 13.37 Mg per ha for SMZ1, SMZ2 and SMZ3, respectively. The gypsum requirement (GR) calculated by (Richards, 1969) as given below. The GR were calculated to give final a value of exchangeable sodium percent (ESP) of 10, the initial ESP are presented in table 5 .

$$
G R=\frac{\text { Initial } E S P-\text { Final } E S P}{100} \times C E C
$$

Where GR = gypsum requirements as $\mathrm{cmol}_{\mathrm{c}} \mathrm{kg}^{-1}$ soil, Initial $\mathrm{ESP}=\mathrm{ESP}$ value before application of gypsum, Final ESP = ESP value after application of gypsum (it is kept at 10) and CEC = cation exchange capacity as $\mathrm{cmol}_{\mathrm{c}} \mathrm{kg}^{-1}$ soil.

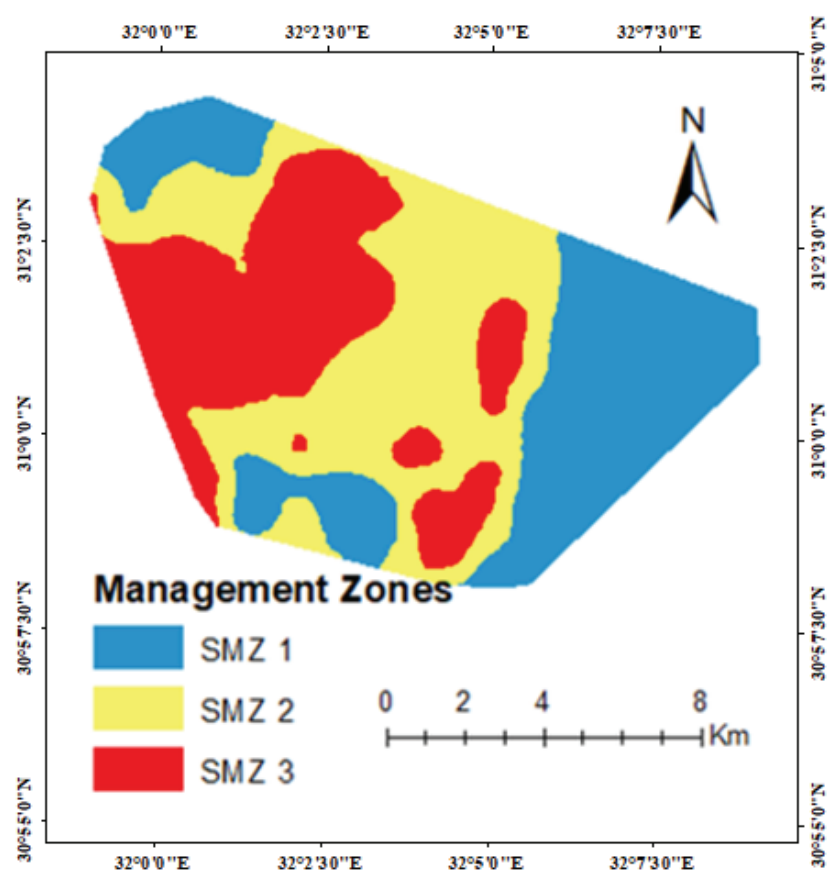

Fig. 8. Soil management zones of the study area.

The amounts of leaching water requirements (LR) required for leaching salts from the soil are 2.98, 4.25 and $5.57 \mathrm{~m}^{3} \mathrm{ha}^{-1}$ $(\times 1000)$ for SMZ1, SMZ2 and SMZ3 respectively. Amounts of leaching water requirements calculated by Reeve equation (Reeve, 1957) as given below. The LR were calculated to give final a value of soil $\mathrm{EC}_{\mathrm{e}}$ of $2 \mathrm{dS} \mathrm{m}^{-1}$, the initial soil $\mathrm{EC}_{\mathrm{e}}$ are presented in table 5 .

$$
\frac{D_{i w}}{D_{s}}=\frac{\text { Initial } E C_{e}}{5 \times \text { Final } E C_{e}}+0.15
$$

Where $\mathrm{D}_{\mathrm{lw}}$ = the depth of leaching water, $\mathrm{D}_{\mathrm{s}}=$ depth of soil (it is kept at $30 \mathrm{~cm}$ ), Initial $\mathrm{EC}_{\mathrm{e}}=$ salinity in $\mathrm{dS}^{-1}$ before leaching and Final $\mathrm{EC}_{\mathrm{e}}=$ salinity in $\mathrm{dS} \mathrm{m}^{-1}$ after leaching (it is kept at $2 \mathrm{dS} \mathrm{m}^{-1}$ ).

\begin{tabular}{|c|c|c|c|c|c|c|c|c|c|c|}
\hline Zone & $\begin{array}{l}\text { Number of } \\
\text { observations }\end{array}$ & $\begin{array}{l}E C_{e} \\
\left(d S m^{-1}\right)\end{array}$ & $\begin{array}{l}\mathrm{pH} \\
(1: 2.5)\end{array}$ & SAR & $\begin{array}{l}\text { ESP } \\
(\%)\end{array}$ & $\begin{array}{l}\text { CEC } \\
\text { cmol }_{\mathrm{c}} \mathrm{kg} \mathrm{soil}^{-1}\end{array}$ & Soil type & $\begin{array}{l}\% \\
\text { area }\end{array}$ & $\begin{array}{l}\text { GR } \\
\mathrm{Mg} \mathrm{ha}^{-1}\end{array}$ & $\begin{array}{l}\text { LR, } \\
\mathrm{m}^{3} \mathrm{ha}^{-1} \times 1000\end{array}$ \\
\hline 1 & 47 & $8.44 \mathrm{c}$ & $7.95 \mathrm{ab}$ & $13.16 \mathrm{~b}$ & $15.32 \mathrm{~b}$ & $28.03 \mathrm{~b}$ & Saline sodic soil & 39.7 & 6.10 & 2.98 \\
\hline 2 & 36 & $12.67 \mathrm{~b}$ & $7.85 \mathrm{~b}$ & $12.95 \mathrm{~b}$ & $15.09 \mathrm{~b}$ & $33.82 \mathrm{a}$ & Saline sodic soil & 33.5 & 7.05 & 4.25 \\
\hline 3 & 42 & $17.08 \mathrm{a}$ & $8.07 \mathrm{a}$ & $17.45 \mathrm{a}$ & $19.64 \mathrm{a}$ & $33.88 \mathrm{a}$ & Saline sodic soil & 26.7 & 13.4 & 5.57 \\
\hline$P$ value & & 0.000 & 0.001 & 0.000 & 0.000 & 0.000 & & & & \\
\hline Significant & & Yes & Yes & Yes & Yes & Yes & & & & \\
\hline
\end{tabular}

Table 5. Soil properties average of variables per management zone

Note: The means followed by the same letter in each column are not significantly different from each other at the 5-percent probability level (Duncan's multiple range test). 


\section{Conclusions}

The Soil samples of the 125 locations in Sahl El-Husseinia, El-Sharkia Governorate, Egypt were analyzed and GPS device was used to record the latitude and longitude of each sampling point. A positive strong significant correlation was observed between ECe and other attributes of soil (i.e. ESP, SAR and CEC) with the exception of $\mathrm{pH}$. The principal component analysis (PCA) resulted that there are two principal components (PCs) explained $80.27 \%$ of the total variance of soil properties. The first PC (explained 59.64\% of variability) was strongly influenced by soil EC $\mathrm{e}$, SAR, ESP and CEC whereas the second PC showed a more intense relation with $\mathrm{pH}$ only. Soil $\mathrm{EC}_{\mathrm{e}}, \mathrm{pH}$ and $\mathrm{CEC}$ were pentaspherical, exponential and stable respectively as a best-fit model whereas the spherical model was the best-fit model to SAR and ESP. Based on the agglomerative hierarchical clustering, three soil management zones (SMZ) were selected differing significantly with respect to studied soil properties. Calculations for each SMZ concerning gypsum requirements to reduce ESP to 10 as well as water amount were conducted to reduce $\mathrm{EC}_{\mathrm{e}}$ to $2 \mathrm{dS} \mathrm{m}^{-1}$. The amounts of agricultural gypsum are 6.10, 7.05 and $13.37 \mathrm{Mg} \mathrm{ha}^{-1}$ for SMZ1, SMZ2 and SMZ3 respectively. The amounts of leaching water requirements (LR) required for leaching salts from the soil are 2.98, 4.25 and $5.57 \mathrm{~m}^{3}$ $\mathrm{ha}^{-1}(\times 1000)$ for SMZ1, SMZ2 and SMZ3 respectively.

\section{References}

Abdi, H., Williams, L. J., 2010. Principal component analysis. John Wiley \& Sons, Inc., 2, 433-459. https://doi.org/10.1002/wics.101

Behera, S.K., Mathur, R.K., Shukla, A.K., Suresh, K., Prakash, C., 2018. Spatial variability of soil properties and delineation of soil management zones of oil palm plantations grown in a hot and humid tropical region of southern India. Catena 165, 251-259. https://doi.org/10.1016/j. catena.2018.02.008

Bekele, A., Hudnall, W.H., 2006. Spatial variability of soil chemical properties of a prairie-forest transition in Louisiana. Plant and Soil 280, 7-21. https://doi.org/10.1007/s11104-005-4983-4

Burrough, P., 1983. Problems of superimposed effects in the statistical study of the spatial variation of soil. Agricultural Water Management 6, 123-143. https://doi.org/10.1016/0378-3774(83)90004-5

Burrough, P.A., 1989. Fuzzy mathematical methods for soil survey and land evaluation. Journal of Soil Science 40, 477-492. https://doi. $\operatorname{org} / 10.1111 / \mathrm{j} .1365-2389.1989 . t b 01290 . x$

Camacho-Tamayo, J.H., Luengas, C.A., Leiva, F.R., 2008. Effect of agricultural intervention on the spatial variability of some soils chemical properties in the eastern plains of Colombia. Chilean Journal of Agricultural Research 68, 42-55. https://doi.org/10.4067/S071858392008000100005

Cambardella, C. et al., 1994. Field-scale variability of soil properties in central Iowa soils. Soil Science society of America Journal 58, 15011511. https://doi.org/10.2136/sssaj1994.03615995005800050033x

Corwin, D., Lesch, S., 2005. Characterizing soil spatial variability with apparent soil electrical conductivity: I. Survey protocols. Computers and Electronics in Agriculture 46, 103-133. https://doi.org/10.1016/j. compag.2004.11.002

Cruz, J.S., Júnior, R.N.A., Matias, S.S.R., Camacho-Tamayo, J.H., 2011. Spatial variability of an Alfisol cultivated with sugarcane. Ciencia e Investigación Agraria 38, 155-164. https://doi.org/10.4067/S071816202011000100015.
De la Rosa, D., 1979. Relation of several pedological characteristics to engineering qualities of soil. Journal of Soil Science 30, 793-799. https:// doi.org/10.1111/j.1365-2389.1979.tb01028.x

Elaalem, M., 2017. Spatial Variability of Some Soil Chemical Proprieties in Jeffara Plain, Libya (Case Study: Tripoli, Wadi Almjainin and Bin Ghashir). Libyan Journal of Agricultural Sciences, 22, 19-34.

Fahad, A.A.S., R. M.; Al-Siaykaly, A. A. and Razaq, I. B., 1993. Spatial Variability of Field Soil Salinity Using Geostatistical Techniques. Basra, Journal Agricultural Science, 6, 1.

Fraisse, C., Sudduth, K., Kitchen, N., Fridgen, J., 1999. Use of unsupervised clustering algorithms for delineating within field management zones. ASAE Paper No. 993043. In 'International Meeting'. Toronto, Ontario, Canada, 18-21 July. (American Society of Agricultural Engineers: St. Joseph, MI).

Goovaerts, P., 1997. Geostatistics for Natural Resources Evaluation. Oxford University Press, New York. https://doi.org/10.1017/ S0016756898631502

Goovaerts, P., 1998. Geostatistical tools for characterizing the spatial variability of microbiological and physico-chemical soil properties. Biology and Fertility of Soils 27, 315-334. https://doi.org/10.1007/ s003740050439

Gundogdu, K.S., Guney, I., 2007. Spatial analyses of groundwater levels using universal kriging. Journal of Earth System Science 116, 49-55. https://doi.org/10.1007/s12040-007-0006-6

Hosseini, E., Gallichand, J., Marcotte, D., 1994. Theoretical and experimental performance of spatial interpolation methods for soil salinity analysis. Transactions of the ASAE 37, 1799-1807. https://doi. org/10.13031/2013.28269

Jabro, J., Stevens, W., Evans, R., Iversen, W., 2010. Spatial variability and correlation of selected soil properties in the Ap horizon of a CRP grassland. Applied Engineering in Agriculture 26, 419-428. https:// doi.org/10.13031/2013.29957

Johnston, K., Hoef, J.M.V., Krivoruchko, K., Lucas. N., 2001. Using ArcGIS Geostatistical Analysis. GIS User Manual by ESRI, New York.

Kerry, R., Oliver, M., 2004. Average variograms to guide soil sampling. International Journal of Applied Earth Observation and Geoinformation 5, 307-325. https://doi.org/10.1016/j.jag.2004.07.005

Knotters, M., Brus, D., Voshaar, J.O., 1995. A comparison of kriging, co-kriging and kriging combined with regression for spatial interpolation of horizon depth with censored observations. Geoderma 67, 227-246. https://doi.org/10.1016/0016-7061(95)00011-C

Li, J., Heap, A.D., 2008. A review of spatial interpolation methods for environmental scientists. Geoscience Australia, Record 2008/23, 137 pp.

López-Granados, F., Jurado-Expósito, M., Atenciano, S., García-Ferrer, A., de la Orden, M. S., and García-Torres, L., 2002. Spatial variability of agricultural soil parameters in southern Spain. Plant and Soil 246, 97-105. https://doi.org/10.1023/A:1021568415380

Oliver, M., 2010. Geostatistical Applications for Precision Agriculture. Springer, New York, Berlin, Heidelberg and Tokyo. https://doi. org/10.1007/978-90-481-9133-8

Overstreet, R., Martin, J.C., King, H.M., 1951. Gypsum, sulfur, and sulfuric acid for reclaiming an alkali soil fo the Fresno series. Hilgardia 21(5):113-127. https://doi.org/10.3733/hilg.v21n05p113

Reeve, R.C., 1957. The relation of salinity to irrigation and drainage requirements. In: Proc. 3rd Int. Congr. Irrigation and Drainage, San Francisco, 10, 175-187.

Richards, L.A., 1969. Diagnosis and improvement of saline and alkali soils. United States Department Of Agriculture, Washington. https:// doi.org/10.1097/00010694-195408000-00012

Santra, P., Chopra, U., Chakraborty, D., 2008. Spatial variability of soil properties and its application in predicting surface map of hydraulic parameters in an agricultural farm. Current Science, 95, 7, 937-945

Stein, A., Hoogerwerf, M., Bouma, J., 1988. Use of soil-map delineations to improve (co-) kriging of point data on moisture deficits. Geoderma 43, 163-177. https://doi.org/10.1016/0016-7061(88)90041-9 
Talkkari, A., Jauhiainen, L., Yli-Halla, M., 2002. Geostatistical prediction of clay percentage based on soil survey data. Agricultural and Food Science 11, 381-390. https://doi.org/10.23986/afsci.5738

Templeton, G.F., 2011. A Two-Step Approach for Transforming Continuous Variables to Normal: Implications and Recommendations for IS Research. Communications of the Association for Information Systems 28(4), 41-58. https://doi.org/10.17705/1CAIS.02804

Usowicz, B., Hajnos M., Sokołowska, Z., Józefaciuk, G., Bowanko, G., Kossowski, J., 2004. Spatial variability of physical and chemical soil properties in a field and commune scale. Acta Agrophysica, Rozprawy i monografie 103, 337-247.
Van Reeuwijk, L.P., 2002. Procedures for soil analysis. No. 9. International Soil Reference and Information Centre.

Verfaillie, E., Van Lancker, V., Van Meirvenne, M., 2006. Multivariate geostatistics for the predictive modelling of the surficial sand distribution in shelf seas. Continental Shelf Research 26, 2454-2468. https:// doi.org/10.1016/j.csr.2006.07.028

White, J., Welch, R., Norvell, W., 1997. Soil zinc map of the USA using geostatistics and geographic information systems. Soil Science Society of America Journal 61, 185-194. 